\title{
Proliferation and estrogen signaling can distinguish patients at risk for early versus late relapse among estrogen receptor positive breast
} cancers

\author{
Giampaolo Bianchini $i^{*}$, Lajos Pusztai ${ }^{2}$, Thomas Karn ${ }^{3}$, Takayuki Iwamoto $^{4}$, Achim Rody ${ }^{5}$, Catherine M Kelly ${ }^{6}$, \\ Volkmar Müller ${ }^{7}$, Marcus Schmidt ${ }^{8}$, Yuan Qi ${ }^{9}$, Uwe Holtrich ${ }^{9}$, Sven Becker ${ }^{9}$, Libero Santarpia ${ }^{10}$, Angelica Fasolo ${ }^{1}$, \\ Gianluca Del Conte ${ }^{1}$, Milvia Zambetti ${ }^{1}$, Christos Sotiriou ${ }^{11}$, Benjamin Haibe-Kains ${ }^{12}$, W Fraser Symmans ${ }^{9}$ \\ and Luca Gianni ${ }^{1}$
}

\begin{abstract}
Introduction: We examined if a combination of proliferation markers and estrogen receptor (ER) activity could predict early versus late relapses in ER-positive breast cancer and inform the choice and length of adjuvant endocrine therapy.
\end{abstract}

Methods: Baseline affymetrix gene-expression profiles from ER-positive patients who received no systemic therapy $(n=559)$, adjuvant tamoxifen for 5 years (cohort-1: $n=683$, cohort-2: $n=282$ ) and from 58 patients treated with neoadjuvant letrozole for 3 months (gene-expression available at baseline, 14 and 90 days) were analyzed. A proliferation score based on the expression of mitotic kinases (MKS) and an ER-related score (ERS) adopted from Oncotype DX ${ }^{\circledR}$ were calculated. The same analysis was performed using the Genomic Grade Index as proliferation marker and the luminal gene score from the PAM50 classifier as measure of estrogen-related genes. Median values were used to define low and high marker groups and four combinations were created. Relapses were grouped into time cohorts of $0-2.5,0-5,5-10$ years.

Results: In the overall 10 years period, the proportional hazards assumption was violated for several biomarker groups indicating time-dependent effects. In tamoxifen-treated patients Low-MKS/Low-ERS cancers had continuously increasing risk of relapse that was higher after 5 years than Low-MKS/High-ERS cancers [0 to 10 year, HR 3.36; $p=0.013]$. High-MKS/High-ERS cancers had low risk of early relapse [0-2.5 years HR 0.13; $p=0.0006]$, but high risk of late relapse which was higher than in the High-MKS/Low-ERS group [after 5 years HR 3.86; $p=0.007$ ]. The High-MKS/Low-ERS subset had most of the early relapses [0 to 2.5 years, HR 6.53; $p<0.0001$ ] especially in node negative tumors and showed minimal response to neoadjuvant letrozole. These findings were qualitatively confirmed in a smaller independent cohort of tamoxifen-treated patients. Using different biomarkers provided similar results.

Conclusions: Early relapses are highest in highly proliferative/low-ERS cancers, in particular in node negative tumors. Relapses occurring after 5 years of adjuvant tamoxifen are highest among the highly-proliferative/high-ERS tumors although their risk of recurrence is modest in the first 5 years on tamoxifen. These tumors could be the best candidates for extended endocrine therapy.

\footnotetext{
* Correspondence: Bianchini.Giampaolo@hsr.it

'San Raffaele - Scientific Institute, Milan, Italy

Full list of author information is available at the end of the article
} 


\section{Introduction}

A sizable risk of late recurrence exists in estrogen receptor (ER)-positive breast cancers after completion of 5 years of adjuvant tamoxifen therapy $[1,2]$. This justifies consideration of extended endocrine treatment in ER-positive early-stage cancers. Letrozole after 5 years of tamoxifen was found to reduce recurrence and improve overall survival [1], demonstrating that some micrometastatic foci retain sensitivity to endocrine therapy even after 5 years of tamoxifen. Continuing tamoxifen to 10 years has also demonstrated an overall survival benefit compared to 5 years of tamoxifen [2]. However, the small absolute benefit should be weighted against the potential side effects of prolonged endocrine therapy [3]. Available molecular markers do not identify patients who are at high risk for late recurrence (after 5 yrs) who would be the best candidates for extended endocrine therapy. While the assays of Recurrence Score and PAM50 predict prognosis for over 10 years, they are most prognostic in the first 5 years and have limited predictive values for late relapses $[4,5]$. Both tests rely on measuring genes associated with proliferation and estrogen receptor signaling $[4,5]$. However, the combination of these markers in these tests is fixed and does not allow detection of time-varying effect or interactions between markers. Given the independent prognostic and predictive values of proliferation and estrogen signaling, we examined in a time-dependent way whether a combination of proliferation, measured by the Mitotic Kinase Gene Expression Score (MKS), and ER-related gene expression, measured by an estrogenrelated gene expression score (ERS), could improve the ability of these variables to predict early versus late relapses in women with ER-positive breast cancer. This information could help in selecting patients for extended adjuvant endocrine therapy based on their persistent risk for late relapses.

\section{Methods}

Tumor samples

Publicly available Affymetrix gene expression data from 683 patients (cohort 1; GSE6532 [6] GSE9195 [7] GSE17705 [8] and GSE12093 [9]) with ER-positive breast cancers treated with 5 years adjuvant tamoxifen and 559 ER-positive, untreated, node-negative breast cancers (GSE2034 [10] GSE7390 [11] GSE11121 [12] GSE5327 [13] GSE2990 [14] and GSE6532 [6]) were analyzed. Duplicated patients were removed from the different datasets. We also assessed an independent series of ER-positive patients treated with adjuvant tamoxifen for 5 years (cohort $2, \mathrm{n}=282$, GSE26971 [15]) and 58 ER-positive patients treated with neoadjuvant letrozole for 3 months for which gene expression profiles are available at baseline, 14 and 90 days after beginning of the neoadjuvant treatment (GSE20181 [16]). In this series, patients with a volume reduction higher than
$50 \%$ over the 3-month treatment period were considered as clinical responders.

Although of limited sample size, cohort 2 was added to our analysis to provide a qualitative confirmation of our findings. Multivariate analysis of this series was not feasible due to the small number of late events $(n=18)$. Gene expression data used in this study were publicly available and ethical approvals have been obtained as reported in the original publications to which the datasets referred.

\section{Description of molecular marker used for analysis}

The proliferation score was calculated as the average expression of 12 mitotic kinases to produce the MKS as previously described [17]. The ERS was defined as the average expression of the four genes from the ER-associated group of the Oncotype DX test (Additional file 1: Table S1) [18]. None of these gene scores was developed or optimized on the current data and therefore our results represent an independent validation of their predictive and prognostic values. To avoid over-fitting of an arbitrary marker threshold to the data, median values were calculated over the combined series of untreated patients and cohort 1 of the tamoxifen-treated patients, and used to define high (that is, above the median) and low (that is, below the median) expression groups. A similar approach was used in cohort 2. By combining these two metrics, four biomarker groups were created (low-MKS/high-ERS; low-MKS/low-ERS; high-MKS/high-ERS and high-MKS/low-ERS).

In order to assess the robustness of our findings, we also tested other measures of proliferation and ER signaling (Additional file 1: Table S1) [19]. We assessed the ability of four previously reported gene signatures to predict early versus late relapse including the PAM50 subtypes [19], the GGI (Genomic Grade Index) [14], the MammaPrint [20] and the three-gene classifier (ER, human epidermal growth factor receptor 2 (HER2) and Aurora Kinase A (AURKA) [21] (Additional file 2: Supplementary Methods).

\section{Statistical analysis}

Statistical analyses were performed using BRB-ArrayTools v4.1.0 - Beta_3 Release [22] and R software v2.9.0. All statistical tests were two-sided. Distant event-free survival was the primary endpoint. For each biomarker, the proportional hazards assumption for Cox regression model was assessed based on the scaled Schoenfeld residuals.

In order to assess the time-dependent prognostic value of our biomarkers groups, we examined recurrences rates in three distinct time intervals, including 0.0 to 2.5 years, 0.0 to 5.0 years and 5.0 to 10.0 years. These intervals were selected because they correspond to clinically important decision points. Patients at high risk for relapse after 5 years of tamoxifen (that is, late relapse) may be the optimal candidates for extended 
adjuvant endocrine therapy. The period from 0.0 to 2.5 years before the conventional switch to aromatase inhibitors is when the selection of the upfront endocrine treatment (tamoxifen versus aromatase inhibitors) is made. Landmark analysis of the Kaplan-Meier estimates by biomarker groups in different time intervals was used. The estimates of the hazard function by biomarker groups were performed using the 'muhaz' R package (v 1.2.5) [23]. The univariate and multivariate hazard ratios were estimated using Cox regression analysis by the Wald test.

\section{Results}

Patient characteristics and correlation between clinical and molecular variables

DEFS information was available for 673 of the 683 patients who received adjuvant tamoxifen in cohort 1 . The median follow up was 9.15 years. DEFS information was available for 553 of the 559 patients who did not receive systemic adjuvant therapy and their median follow up was 9.9 years. The treated (cohort 1) and untreated patient cohorts were significantly different in age, tumor (T) size, nodal status and histological grade (Table 1).

There was no association between the four molecular groups (low-MKS/high-ERS, low-MKS/low-ERS, highMKS/high-ERS and high-MKS/low-ERS), nodal status or age. However, high-MKS cancers had higher grade and larger T size (T2/T3). The majority of HER2-positive tumors $(77.5 \%)$ were in the high-MKS/low-ERS group.

\section{Time-varying prognostic values of clinical and molecular} variables in adjuvant tamoxifen-treated patients

We assessed the prognostic values of clinical and molecular variables for 10 years DEFS using Cox analysis in tamoxifen-treated patients (cohort 1) and tested the assumption of proportional hazards for each model (Table 2). Age, T size and nodal status did not violate the proportional hazards assumption but some molecular variables showed violation of the proportional hazard assumption indicating that their prognostic values varied over time.

We divided the time axis into less than 5 and 5 to 10 years and estimated the hazard ratios (HRs) separately for each variable in both time periods. High-proliferation tumors had a higher risk of relapse during the entire period, but the risk decreased significantly over time. HER2-positive tumors had a higher risk of relapse only during the first 5 years. The ERS also had a strong time dependent effect ( $P=0.0008$ over 10 years). The HRs for recurrence of low- versus high-ERS groups in the first 2.5 years, from 2.5 to 5.0 years, and $>5.0$ years were 8.36 (95\% CI 3.37, 21.7), 1.93 (95\% CI 1.07, 3.48) and 0.91 (95\% CI 0.50, 1.66), respectively. The four-group model obtained by combining MKS and ERS had the strongest time-dependent effect $(P<0.0001)$. Kaplan-Meier analysis of the four biomarker groups is represented in Figure 1 for the tamoxifen-treated patients (Figure 1A). The timedependent effect of biomarkers was qualitatively similar in node-negative (Figure 1B) and -positive (Figure 1C) tumors.

\section{Time-varying prognostic values of clinical and molecular variables in untreated patients}

We performed a similar analysis in patients who received no adjuvant therapy (Additional file 3: Table S2). Age and T size did not violate the proportional hazards assumption over 10 years. The low-ERS group had a constant, slightly higher risk of recurrence than the high-ERS group in the first 5 years (HR 1.90, 95\% CI 1.29, 2.80; $P=0.001$ ) without a significant violation of the proportional hazard assumption $(P=0.127)$. High-proliferation tumors (that is, high histological grade, high-MKS, high-GGI, luminal B) had a higher risk of relapse over the entire 10-year period, but the risk decreased significantly after the first 5 years. There was a trend for a higher relative rate of relapse in low proliferation tumors after 5 years (Additional file 4: Figure S1). In the absence of endocrine therapy, the four-group model had only a trend for time-dependent effect $(P=0.065)$ (Figure 1D).

\section{Prediction of early and late relapse in tamoxifen-treated patients}

Among the tamoxifen-treated patients, cancers with low proliferation and low ERS were associated with a continuously increasing risk of relapse over 10 years (Table 2), that was higher between 5 to 10 years than in 0 to 5 years (HR 3.36, 95\% CI $1.29,8.73 ; P=0.013$ ) (Additional file 4: Figure S2A). Low proliferation and high-ERS tumors had an excellent prognosis at 10 years, even after stopping tamoxifen at 5 years (Figure 1). In the high-proliferation group, ERS had an even stronger time-dependent prognostic value $(P<0.0001)$. Among high proliferation cancers, the HRs for the low- versus high-ERS groups in the time periods 0.0 to $2.5,2.5$ to 5.0 , and $>5.0$ to 10.0 years were $11.8,95 \%$ CI 2.83, 49.3; $P=0.0007,1.80$, 95\% CI 0.88, 3.69; $P=0.110$, and $0.23,95 \%$ CI 0.08 , $0.61 ; P=0.003)$, respectively indicating very high risk of early relapse among high-proliferation low-ESR cancers (Additional file 4: Figure S2A). This was similar in node-negative (Figure 2A) and -positive (Figure 2B) patients. To test if this effect was independent of the threshold used, we also examined the time dependence when ESR was assessed by tertiles or as continuous variables. The lowest tertile of ERS compared to the highest showed a higher risk of early relapse within 0 to 5 years (HR 3.93, 95\% CI 1.99, 7.75; $P<0.0001$ ) and a lower risk of late relapse between 5 to 10 years (HR 0.09, 95\% CI 0.01, $0.70 ; P=0.021$ ) (Additional file 4: Figure S3). ERS analyzed as a continuous variable produced similar results, indicating a robust finding. 
Table 1 Summary of patient and tumor characteristics

\begin{tabular}{|c|c|c|c|c|c|c|c|c|c|c|c|c|c|c|c|c|}
\hline \multirow[b]{3}{*}{ Characteristic } & \multirow{2}{*}{\multicolumn{2}{|c|}{$\begin{array}{c}\text { Tamoxifen } \\
\text { cohort } 1\end{array}$}} & \multirow{2}{*}{\multicolumn{2}{|c|}{ Untreated }} & \multirow[b]{3}{*}{$P^{a}$} & \multicolumn{4}{|c|}{ Low MKS } & \multicolumn{4}{|c|}{ High MKS } & \multirow[b]{3}{*}{$P^{b}$} & \multirow{2}{*}{\multicolumn{2}{|c|}{$\begin{array}{c}\text { Tamoxifen } \\
\text { cohort } 2\end{array}$}} \\
\hline & & & & & & \multicolumn{2}{|c|}{ High ERS } & \multicolumn{2}{|c|}{ Low ERS } & \multicolumn{2}{|c|}{ High ERS } & \multicolumn{2}{|c|}{ Low ERS } & & & \\
\hline & $\mathrm{N}$ & $\%$ & $\mathrm{~N}$ & $\%$ & & $\mathrm{~N}$ & $\%$ & $\mathrm{~N}$ & $\%$ & $\mathrm{~N}$ & $\%$ & $\mathrm{~N}$ & $\%$ & & $\mathrm{~N}$ & $\%$ \\
\hline Patients & 683 & & 559 & & & 373 & & 248 & & 248 & & 373 & & & 282 & \\
\hline \multicolumn{17}{|l|}{ Age, years } \\
\hline$\leq 50$ & 43 & 6.3 & 240 & 42.9 & $<0.0001$ & 82 & 22.0 & 47 & 19.0 & 57 & 23.0 & 96 & 25.7 & 0.247 & 8 & 2.8 \\
\hline$>50$ & 498 & 72.9 & 306 & 54.8 & & 240 & 64.3 & 172 & 69.3 & 160 & 64.5 & 233 & 62.5 & & 176 & 62.4 \\
\hline Unknown & 142 & 20.8 & 13 & 2.3 & & 51 & 13.7 & 29 & 11.7 & 31 & 12.5 & 44 & 11.8 & & 98 & 34.8 \\
\hline \multicolumn{17}{|l|}{ Tumor $(\mathrm{T})$ stage } \\
\hline $\mathrm{T} 1$ & 214 & 31.3 & 199 & 35.6 & $<0.0001$ & 145 & 38.9 & 102 & 41.1 & 74 & 29.8 & 92 & 24.7 & 0.003 & 109 & 38.7 \\
\hline $\mathrm{T} 2 / \mathrm{T} 3$ & 293 & 42.9 & 140 & 25.0 & & 126 & 33.8 & 82 & 33.1 & 84 & 33.9 & 141 & 37.8 & & 168 & 59.5 \\
\hline Unknown & 176 & 25.8 & 220 & 39.4 & & 102 & 27.3 & 64 & 25.8 & 90 & 36.3 & 140 & 37.5 & & 5 & 1.8 \\
\hline \multicolumn{17}{|l|}{ Nodal status } \\
\hline Negative & 403 & 59.0 & 559 & 100.0 & $<0.0001$ & 295 & 79.1 & 192 & 77.4 & 191 & 77.0 & 284 & 76.1 & 0.962 & 147 & 52.1 \\
\hline Positive & 258 & 37.8 & 0 & 0.0 & & 76 & 20.4 & 50 & 20.2 & 52 & 21.0 & 80 & 21.5 & & 111 & 39.4 \\
\hline Unknown & 22 & 3.2 & 0 & 0.0 & & 2 & 0.5 & 6 & 2.4 & 5 & 2.0 & 9 & 2.4 & & 24 & 8.5 \\
\hline \multicolumn{17}{|l|}{ Grade } \\
\hline 1 & 108 & 15.8 & 66 & 11.8 & 0.0002 & 86 & 23.1 & 54 & 21.8 & 18 & 7.3 & 16 & 4.3 & $<0.0001$ & 26 & 9.2 \\
\hline 2 & 258 & 37.8 & 242 & 43.3 & & 159 & 42.6 & 105 & 42.3 & 108 & 43.5 & 128 & 34.3 & & 114 & 40.4 \\
\hline 3 & 111 & 16.3 & 152 & 27.2 & & 29 & 7.8 & 32 & 12.9 & 63 & 25.4 & 139 & 37.3 & & 44 & 15.6 \\
\hline Unknown & 206 & 30.2 & 99 & 17.7 & & 99 & 26.5 & 57 & 23.0 & 59 & 23.8 & 90 & 24.1 & & 98 & 34.8 \\
\hline \multicolumn{17}{|l|}{ HER2 by gene ${ }^{c}$} \\
\hline HER2-positive & 27 & 4.0 & 44 & 7.9 & 0.169 & 1 & 0.3 & 8 & 3.2 & 7 & 2.8 & 55 & 14.8 & $<0.0001$ & - & 0.0 \\
\hline HER2-negative & 647 & 94.7 & 515 & 92.1 & & 371 & 99.4 & 239 & 96.4 & 239 & 96.4 & 313 & 83.9 & & - & 0.0 \\
\hline Unknown & 9 & 1.3 & 0 & 0.0 & & 1 & 0.3 & 1 & 0.4 & 2 & 0.8 & 5 & 1.3 & & 282 & 100.0 \\
\hline \multicolumn{17}{|c|}{ Distant events, time cohorts } \\
\hline 0 to $10 \mathrm{yrs}$ & 137 & & 144 & & - & 42 & & 37 & & 65 & & 137 & & - & 64 & \\
\hline 0 to $2.5 \mathrm{yrs}$ & 46 & & 55 & & & 8 & & 9 & & 17 & & 67 & & & 26 & \\
\hline 2.5 to $5 \mathrm{yrs}$ & 48 & & 55 & & & 19 & & 10 & & 21 & & 53 & & & 20 & \\
\hline$>5 \mathrm{yrs}$ & 43 & & 34 & & & 15 & & 19 & & 26 & & 17 & & & 18 & \\
\hline Unknown & 10 & & 6 & & & 2 & & 6 & & 3 & & 5 & & & - & \\
\hline
\end{tabular}

${ }^{a}$ Only patients with known clinical information were considered for comparison between tamoxifen-treated (cohort 1$)$ and untreated patients. ${ }^{b}$ Only patients with known clinical information were considered for comparison among the four molecular groups. $P$-values in boldface were statistically significant at $P<0.05$. These molecular groups referred to the tamoxifen-treated (cohort 1) and untreated patients. 'HER2 status was defined according to Haibe-Kains et al. [21]. N, number of patients; MKS, mitotic kinase score; ERS, estrogen-related score; HER2: human epidermal growth factor receptor 2.

These findings also indicate that the prognostic value of ER-associated genes for late recurrence is different in low- and high-proliferation cancer groups (Additional file 4: Figure S2A). In the 5- to 10-year interval, Cox analysis including MKS and ERS as continuous variables and their interaction term showed that they were each independently significant $(P=0.035$ and $P=0.048$, respectively). The interaction term was also significant $(P=0.027)$. In the 0.0 - to 2.5-year interval, almost all recurrences occurred in the high-MKS/low-ERS group (HR 6.53, 95\% CI 3.48, 12.2; $P<0.0001$ ) compared to other groups (Additional file 4: Figure S4B). In this high-risk group the nodal status was not significantly prognostic $(P=0.098)$ (Additional file 4 :
Figure S4F), but in the other molecular groups enriched for more endocrine-sensitive tumors, almost all relapses were observed in the node-positive cohort (HR 6.56, 95\% CI 1.83, 23.5; $P=0.0008$ ) (Additional file 4: Figure S4E). The average ERS of high-MKS tumors that relapsed at 0.0 to $2.5,2.5$ to 5.0 and $>5.0$ to 10.0 years was progressively and significantly higher in late relapses (Additional file 4: Figure S5B).

Results of a Cox multivariate analysis for the 0.0- to 2.5- and 5.0- to 10.0-year time periods are presented in Table 3. After adjustment for clinical variables, high-MKS/ high-ERS (HR 4.59, 95\% CI 1.56, 13.5; $P=0.006$ ) and low-MKS/low-ERS groups (HR 3.53, 95\% CI 1.21, 10.2; 
Table 2 Univariate Cox analysis of clinical variables and molecular markers for tamoxifen-treated patients (cohort-1)

\begin{tabular}{|c|c|c|c|c|c|c|c|c|c|}
\hline \multirow[t]{2}{*}{ Variable } & \multicolumn{2}{|c|}{0 to 10 years DEFS } & \multirow[b]{2}{*}{$P^{\mathrm{b}}$} & \multicolumn{2}{|c|}{0 to 5 years DEFS } & \multirow[b]{2}{*}{$P^{\mathrm{b}}$} & \multicolumn{2}{|c|}{5 to 10 years DEFS } & \multirow[b]{2}{*}{$P^{\mathrm{b}}$} \\
\hline & $\begin{array}{c}\text { Hazard ratio } \\
(95 \% \mathrm{Cl})\end{array}$ & $P^{a}$ & & $\begin{array}{c}\text { Hazard ratio } \\
(95 \% \mathrm{Cl})\end{array}$ & $P^{a}$ & & $\begin{array}{c}\text { Hazard ratio } \\
(95 \% \mathrm{Cl})\end{array}$ & $P^{a}$ & \\
\hline Age & $1.02(1.00,1.04)$ & 0.021 & 0.657 & $1.02(0.99,1.04)$ & 0.153 & 0.214 & $1.04(1.00,1.08)$ & 0.042 & 0.168 \\
\hline Stage $T 2 / 3$ vs $T 1$ & $2.71(1.76,4.19)$ & $<0.0001$ & 0.581 & $2.51(1.47,4.26)$ & 0.0007 & 0.211 & $3.14(1.49,6.64)$ & 0.003 & 0.164 \\
\hline Node-positive vs -negative & $2.47(1.75,3.48)$ & $<0.0001$ & 0.964 & $2.51(1.65,3.82)$ & $<0.0001$ & 0.732 & $2.67(1.44,4.97)$ & 0.002 & 0.941 \\
\hline \multicolumn{10}{|l|}{ Grade } \\
\hline Intermediate vs low & $2.19(1.20,3.99)$ & 0.011 & 0.11 & $3.97(1.57,9.99)$ & 0.003 & 0.175 & $1.04(0.44,2.45)$ & 0.934 & 0.192 \\
\hline High vs low & $2.96(1.56,5.62)$ & 0.0009 & & $5.05(1.92,13.3)$ & 0.001 & & $1.66(0.67,4.12)$ & 0.277 & \\
\hline HER2-positive vs -negative & $2.64(1.43,4.90)$ & 0.002 & 0.029 & $3.68(1.91,7.10)$ & 0.0001 & 0.369 & $0.72(0.11,5.26)$ & 0.75 & 0.141 \\
\hline High MKS vs low MKS & $2.96(2.07,4.25)$ & $<0.0001$ & 0.04 & $3.89(2.42,6.24)$ & $<0.0001$ & 0.473 & $1.90(1.04,3.46)$ & 0.036 & 0.377 \\
\hline Low ERS vs high ERS & $2.00(1.41,2.83)$ & $<0.0001$ & 0.0008 & $3.26(2.04,5.19)$ & $<0.0001$ & 0.091 & $0.91(0.50,1.66)$ & 0.763 & 0.728 \\
\hline \multicolumn{10}{|l|}{ MKS/ERS combined groups } \\
\hline LOWMKS/lowERS vs lowMKS/highERS & $2.37(1.29,4.35)$ & 0.005 & $<0.0001$ & $1.98(0.87,4.51)$ & 0.104 & 0.285 & $3.36(1.29,8.73)$ & 0.013 & 0.862 \\
\hline HighMKS/highERS vs lowMKS/highERS & $3.66(2.04,6.57)$ & $<0.0001$ & & $2.46(1.09,5.54)$ & 0.029 & & $6.59(2.62,16.6)$ & $<0.0001$ & \\
\hline HighMKS/lowERS vs lowMKS/highERS & $5.35(3.12,9.17)$ & $<0.0001$ & & $7.78(3.97,15.3)$ & $<0.0001$ & & $1.46(0.45,4.79)$ & 0.531 & \\
\hline \multicolumn{10}{|l|}{ Other genomic signatures } \\
\hline High GGI vs low GGI & $2.73(1.94,3.86)$ & $<0.0001$ & 0.005 & $3.81(2.43,5.97)$ & $<0.0001$ & 0.296 & $1.64(0.90,2.99)$ & 0.109 & 0.02 \\
\hline Mammaprint poor vs good & $2.93(1.91,4.49)$ & $<0.0001$ & 0.22 & $3.59(2.02,6.30)$ & $<0.0001$ & 0.768 & $2.30(1.16,4.56)$ & 0.017 & 0.184 \\
\hline \multicolumn{10}{|l|}{ Three-gene model SCMGENE } \\
\hline ER+/HER2-highP vs ER+/HER2-lowP & $2.13(1.47,3.08)$ & $<0.0001$ & 0.017 & $2.58(1.59,4.18)$ & 0.0001 & 0.585 & $1.60(0.87,2.95)$ & 0.127 & 0.197 \\
\hline HER2+ vs ER+/HER2-lowP & $4.06(2.09,7.86)$ & $<0.0001$ & & $6.63(3.17,13.9)$ & $<0.0001$ & & $0.89(0.12,6.64)$ & 0.909 & \\
\hline ER-/HER2- vs ER+/HER2-lowP & $2.55(1.01,6.42)$ & 0.048 & & $4.70(1.79,12.3)$ & 0.002 & & NA & & \\
\hline \multicolumn{10}{|l|}{ PAM50 } \\
\hline LumB vs lumA & $3.01(2.01,4.51)$ & $<0.0001$ & 0.004 & $3.84(2.21,6.65)$ & $<0.0001$ & 0.109 & $2.26(1.20,4.24)$ & 0.011 & 0.147 \\
\hline HER2 vs lumA & $8.88(4.36,18.1)$ & $<0.0001$ & & $14.4(6.37,32.8)$ & $<0.0001$ & & $2.37(0.31,17.9)$ & 0.403 & \\
\hline Basal vs lumA & $3.03(1.07,8.58)$ & 0.036 & & $6.48(2.17,19.4)$ & 0.0008 & & NA & & \\
\hline
\end{tabular}

${ }^{a} P$-value generated by univariate Cox analysis. ${ }^{b} P$-value for the test of the proportional hazard assumption based on the scaled Schoenfeld residuals. $P$-values in boldface were statistically significant at $P<0.05$. DEFS, distant event-free survival; MKS, mitotic kinase score; ERS, estrogen-related score; GGl, genomic grade index; Lum, luminal; ER+/HER2-lowP, ER-positive/human epidermal growth factor receptor 2 (HER2)-negative low proliferation; ER+/HER2-highP, ER-positive/HER2negative high proliferation; NA, not applicable.

$P=0.021$ ) remained at higher risk of late relapses than the low-MKS/high-ERS group.

\section{Prediction of early and late relapse in untreated patients}

ERS was not predictive of early versus late relapse when proliferation (MKS) was low (Additional file 3: Table S2). In the high-MKS group, there was a constantly higher risk of relapse for the low-ERS group over 10 years (HR 1.80, 95\% CI 1.18, 2.73); $P=0.006$ ) (Figure $2 \mathrm{C}$ and Additional file 3: Table S2). In the first 2.5 years, the high-MKS/ low-ERS group had a higher risk of relapse than the other groups combined (Additional file 4: Figure S4A) and the HER2-positive patients were also at significantly higher risk of relapse. Cox multivariate analysis showed that none of the variables was prognostic for late relapse (Table 3). When the average ERS was compared between tumors relapsing at 0.0 - to 2.5-, 2.5- to 5.0- and 5.0- to 10 -year time intervals we did not observe any significant difference by proliferation group (Additional file 4: Figure S5C and S5D).

A combination of proliferation and ER-related genes can further risk-stratify patients for early and late relapse within conventional prognostic risk categories assigned by PAM50 and Mammaprint

To test the robustness of our observations, we performed the same analysis substituting the genomic grade index for MKS as a proliferation marker and the luminal gene score from the PAM50 classifier for the ERS as a measure of estrogen-related genes. Results using the combination of these markers also showed higher risk of early relapse in highly proliferative, low estrogen-score cancers and substantial risk for late relapse in highly proliferative and high estrogen-score tumors (Additional file 4: Figure S6). We also noted that ESR1 mRNA expression levels did not correlate strongly with either the ERS or luminal 


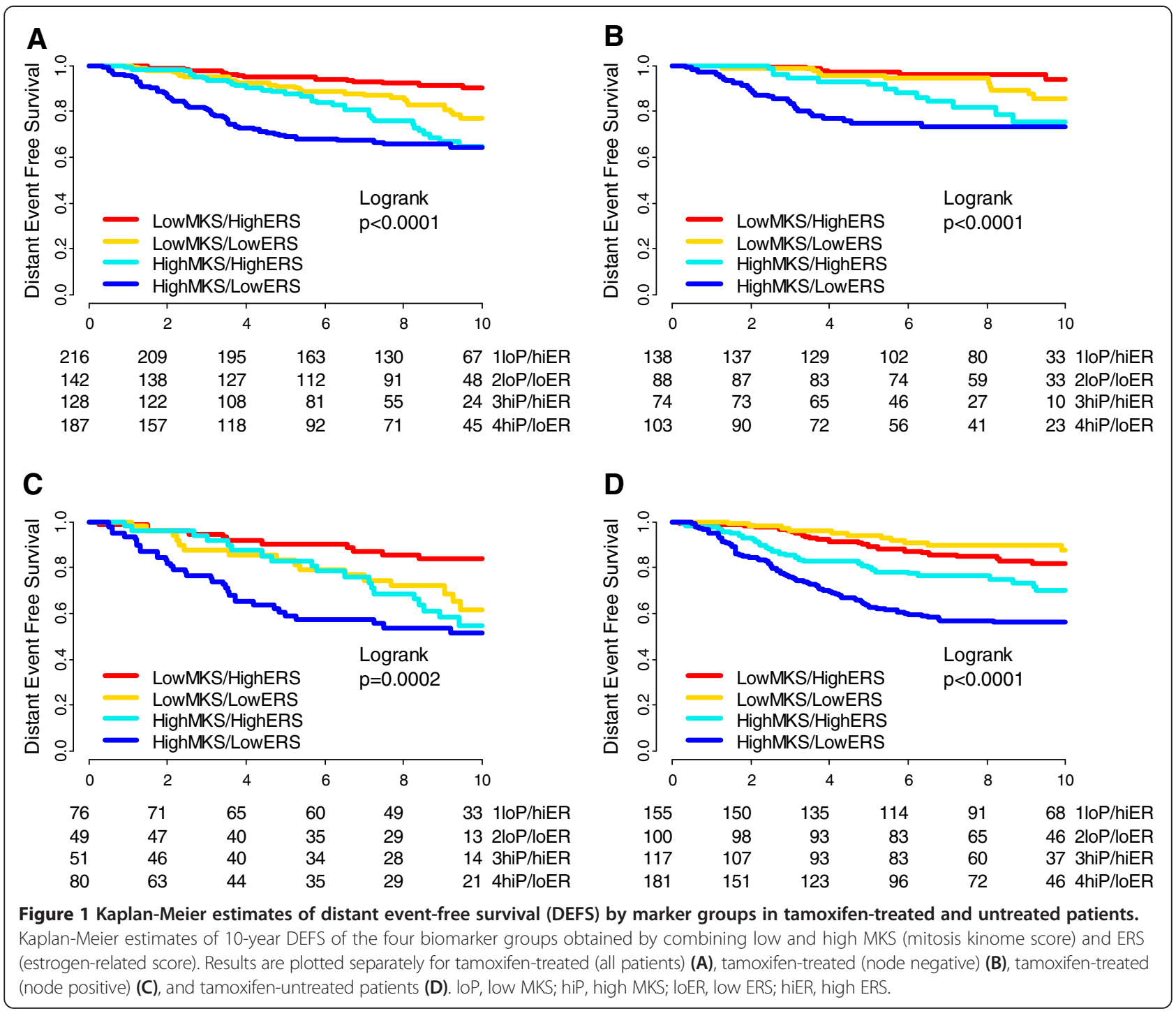

gene scores, an indication that these scores capture molecular information not provided by ESR1 expression levels alone (Additional file 4: Figure S7).

Furthermore, the four biomarker groups based on MKS and ERS could further risk-stratify patients for early ( $<5$ years) and late relapses (within 5 to 10 years) within prognostic risk groups assigned by three first-generation genomic prognostic predictors, including the three-gene model (Figure 3A and 3B), luminal $\mathrm{A}$ and $\mathrm{B}$ molecular subtypes by PAM50 (Figure 3C and 3D) and low- and high-risk groups by Mammaprint (Figure 3E and 3F).

\section{Confirmation of results in an independent cohort of patients treated with adjuvant tamoxifen}

The patient characteristics of an independent series of ER-positive patients treated with adjuvant tamoxifen are described in Table 1. The median follow up was 7.2 years. The median cutoff point was applied to MKS and ERS.
The time-varying pattern of distant relapse was qualitatively similar to that observed in the previously described cohort (Figure 4A-C). In the high-proliferation group the risk of relapse for the high-ERS group was lower in the first 5 years $(P=0.057)$ and higher after 5 years $(P=0.072)$ (Figure 4D). We also confirmed that in the first 2.5 years the majority of the relapses occurred in the high-MKS/ low-ERS groups in node-negative but not in node-positive patients (Additional file 4: Figure S8).

Predictive values of proliferation and ER-associated genes in tumors treated with neoadjuvant letrozole

We evaluated the relationship between MKS and ERS and clinical and molecular response to neoadjuvant letrozole $(n=58)$. Molecular response was defined as downregulation of the MKS, as a measure of proliferation, at 14 and 90 days during neoadjuvant therapy. Among cancers with high proliferation (that is, high 


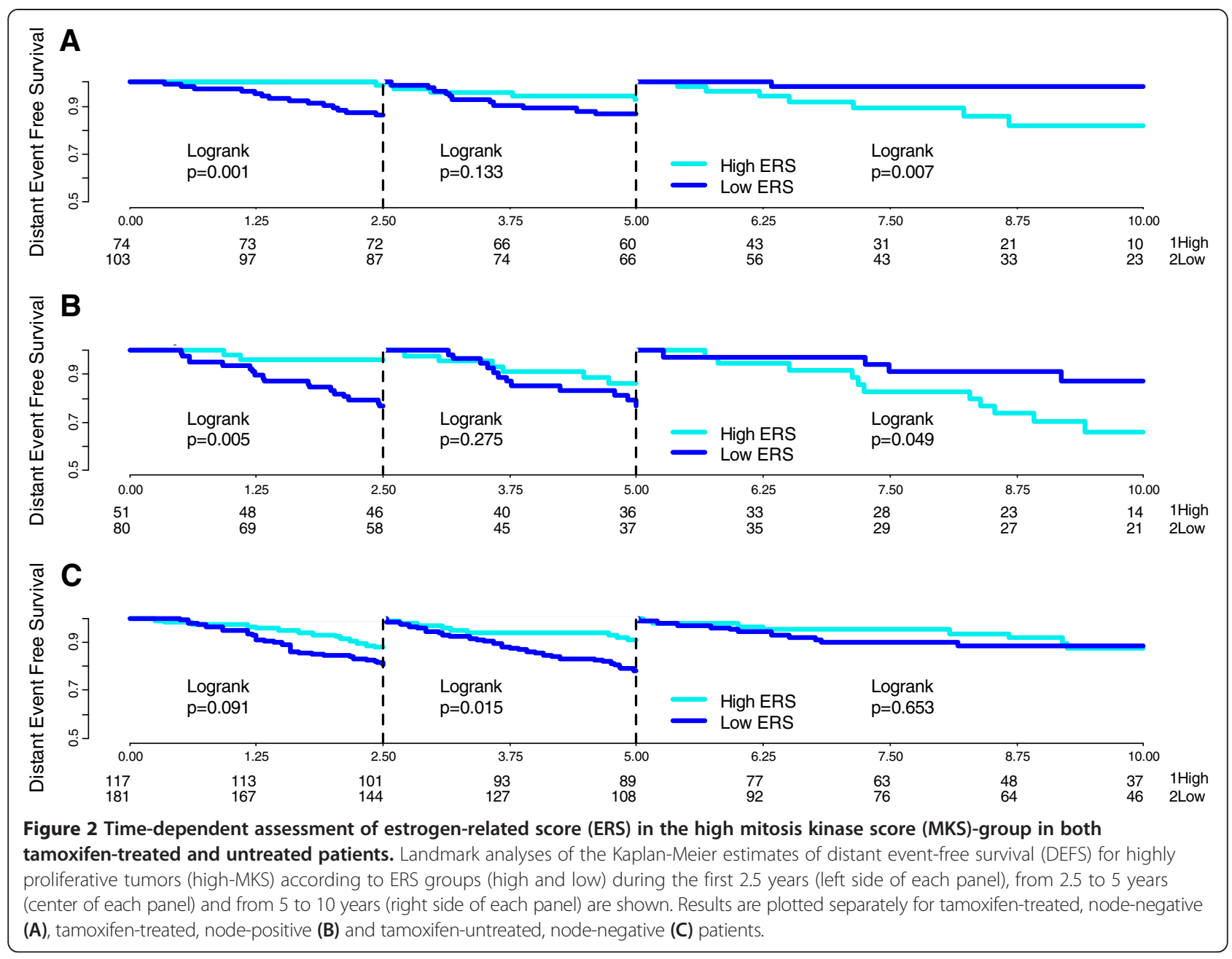

Table 3 Multivariate Cox analysis of clinical variables and marker groups in tamoxifen-treated (cohort 1) and untreated patients

\begin{tabular}{|c|c|c|c|c|c|c|c|c|}
\hline \multirow[b]{3}{*}{ Variable } & \multicolumn{4}{|c|}{ Tamoxifen-treated patients (cohort 1 ) } & \multicolumn{4}{|c|}{ Untreated patients } \\
\hline & \multicolumn{2}{|c|}{0.0 to 2.5 years $^{\mathrm{a}}$} & \multicolumn{2}{|c|}{5.0 to 10.0 years $^{a, c}$} & \multicolumn{2}{|c|}{0.0 to 2.5 years $^{b}$} & \multicolumn{2}{|c|}{5.0 to 10.0 years $^{\mathrm{b}, \mathrm{c}}$} \\
\hline & $\begin{array}{c}\text { Hazard ratio } \\
(95 \% \mathrm{Cl})\end{array}$ & $P$ & $\begin{array}{c}\text { Hazard ratio } \\
(95 \% \mathrm{Cl})\end{array}$ & $P$ & $\begin{array}{c}\text { Hazard ratio } \\
(95 \% \mathrm{Cl})\end{array}$ & $P$ & $\begin{array}{c}\text { Hazard ratio } \\
(95 \% \mathrm{Cl})\end{array}$ & $P$ \\
\hline Age, analyzed as a continuous variable & $1.04(0.99,1.08)$ & 0.071 & $1.02(0.98,1.07)$ & 0.279 & $1.01(0.98,1.05)$ & 0.357 & $1.04(0.99,1.08)$ & 0.063 \\
\hline Tumor (T) stage, T2/3 vs T1 & $2.29(0.87,6.08)$ & 0.094 & $2.90(1.22,6.91)$ & 0.016 & $1.88(0.74,4.80)$ & 0.183 & $1.22(0.48,3.12)$ & 0.677 \\
\hline Nodal status, positive vs negative & $2.92(1.23,6.88)$ & 0.014 & $2.46(1.15,5.23)$ & 0.021 & - & - & & \\
\hline Grade 2 or 3 vs 1 & $1.51(0.33,6.78)$ & 0.592 & $0.72(0.31,1.69)$ & 0.451 & $2.13(0.28,16.4)$ & 0.467 & $1.07(0.29,3.95)$ & 0.923 \\
\hline HER2-positive vs -negative & $1.42(0.33,6.78)$ & 0.528 & $1.63(0.31,1.69)$ & 0.667 & $4.24(1.36,13.1)$ & 0.013 & $2.89(0.57,14.6)$ & 0.198 \\
\hline \multicolumn{9}{|l|}{ MKS/ERS (ref lowMKS/highERS) } \\
\hline lowMKS/lowERS & $2.65(0.48,14.7)$ & 0.269 & $3.53(1.21,10.2)$ & 0.021 & $1.67(0.10,27.1)$ & 0.717 & $0.46(0.09,2.33)$ & 0.349 \\
\hline highMKS/highERS & $1.28(0.18,9.23)$ & 0.807 & $4.59(1.56,13.5)$ & 0.006 & $11.6(1.41,95.2)$ & 0.023 & $1.82(0.53,6.27)$ & 0.3 \\
\hline highMKS/lowERS & $10.0(2.21,45.5)$ & 0.003 & $0.95(0.20,4.70)$ & 0.947 & $9.56(1.17,77.8)$ & 0.035 & $1.51(0.44,5.14)$ & 0.508 \\
\hline
\end{tabular}

Note: only patients with all data available were considered in multivariate analysis. ${ }^{\mathrm{a}}$ Time interval 0.0 to 2.5 years: 434 patients (29 events); time interval 5.0 to 10.0 years: 323 patients ( 34 events). ${ }^{\text {b }}$ Time interval 0.0 to 2.5 years: 320 patients ( 20 events); time interval 5.0 to 10.0 years: 256 patients (19 events). Cox multivariate analysis was performed also excluding tumor stage (which accounted for the majority of the missing data) with similar results (458 patients ( 40 events) and 349 patients ( 28 events) in 0.0 to 2.5 and 5.0 to 10 years, respectively). ${ }^{C} P=0.0002$ (tamoxifen, 0.0 to 2.5 years), $P=0.003$ (tamoxifen, 5.0 to 10.0 years), $P=0.006$ (untreated, 0.0 to 2.5 years), $P=0.361$ (untreated, 5.0 to 10.0 years) for the comparison of the multivariate models with and without the MKS/ERS groups (by the likelihood-ratio test). MKS, mitotic kinase score; ERS, estrogen-related score. $P$-values in boldface were statistically significant at $P<0.05$. 


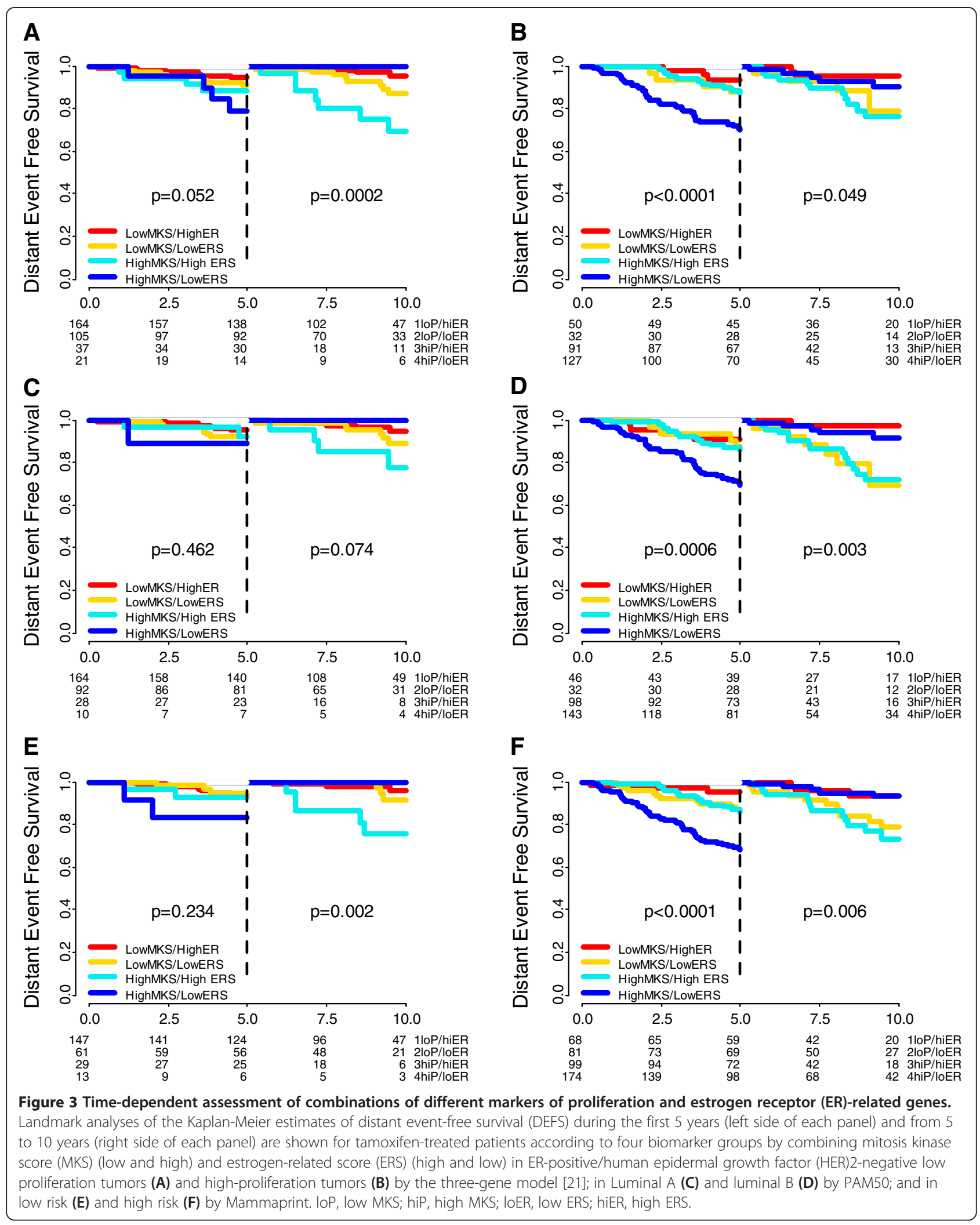


MKS) at baseline $(\mathrm{n}=26)$, the clinical response rates were $47 \%(7 / 15)$ and $100 \%(11 / 11)$ for the low-ERS and high-ERS groups, respectively $(P=0.013)$. High-ERS cancers also had a more significant downregulation of proliferation at $14(P=0.028)$ and at 90 days $(P=0.045)$ compared to low-ERS tumors in response to letrozole therapy (Figure 5). These findings confirm lesser endocrine sensitivity of low-ERS cancers and are consistent with the observation of high early relapse rates among the high MKS/low ERS cancers.

\section{Discussion}

The potential time-dependency of prognostic and predictive variables is well-known $[11,24,25]$, but it is rarely studied purposefully. In this paper we examined the time-dependent interaction of proliferation [17] and ER-related gene expression $[18,26]$ with the risk of early versus late recurrence in ER-positive early-stage breast cancer. We show that the high risk of relapse of highly proliferative tumors decreases over time in both untreated and tamoxifen-treated patients [11,24]. We also discovered a strong time-dependent prognostic interaction between the ERS and proliferation in tamoxifentreated patients. The low risk of early recurrence in highERS, high-proliferation cancers during the first 5 years of active therapy converts into a higher risk of recurrence after 5 years. Highly proliferative cancers with strong ER signaling (high-MKS/high-ERS) show the greatest

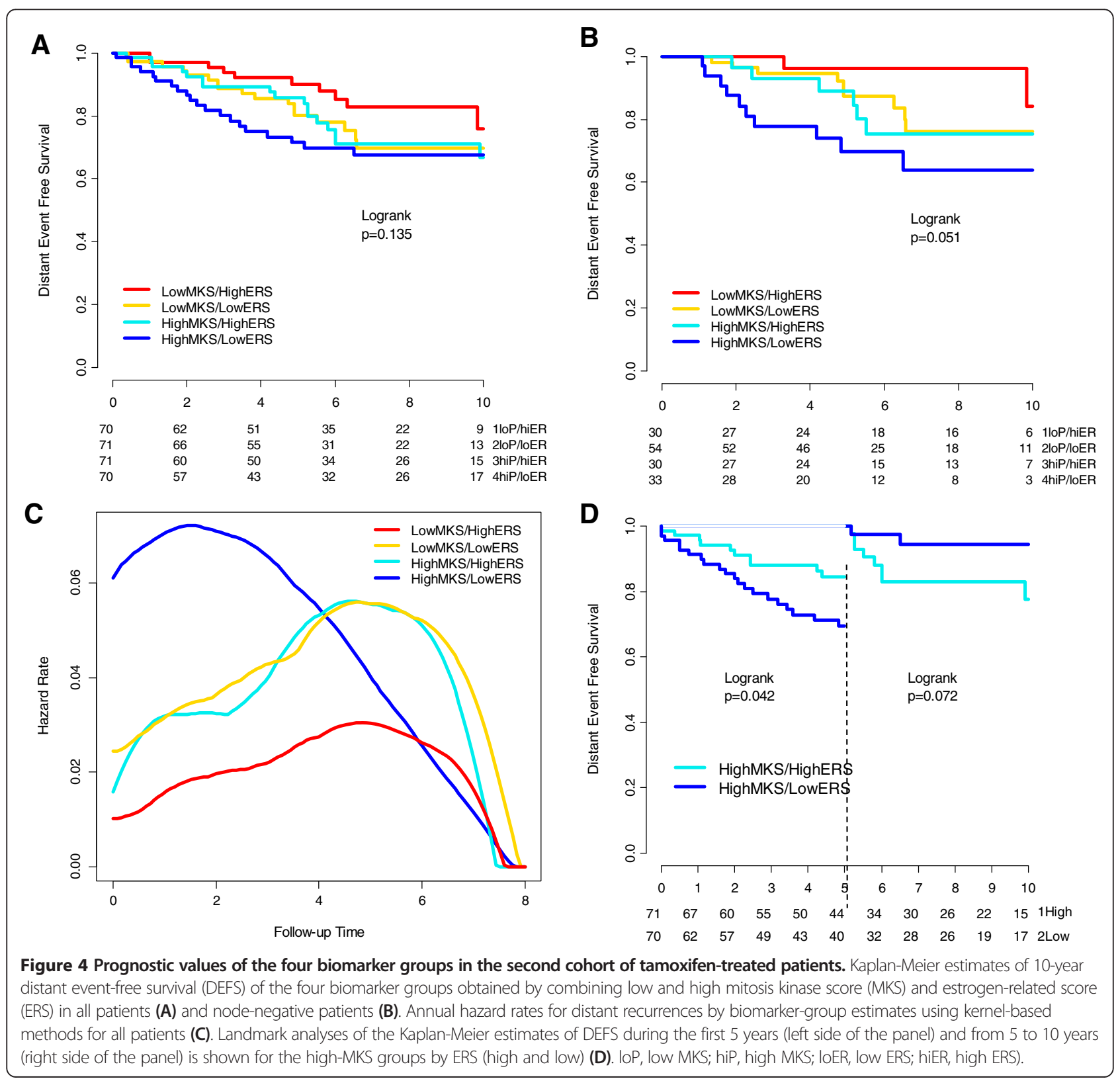




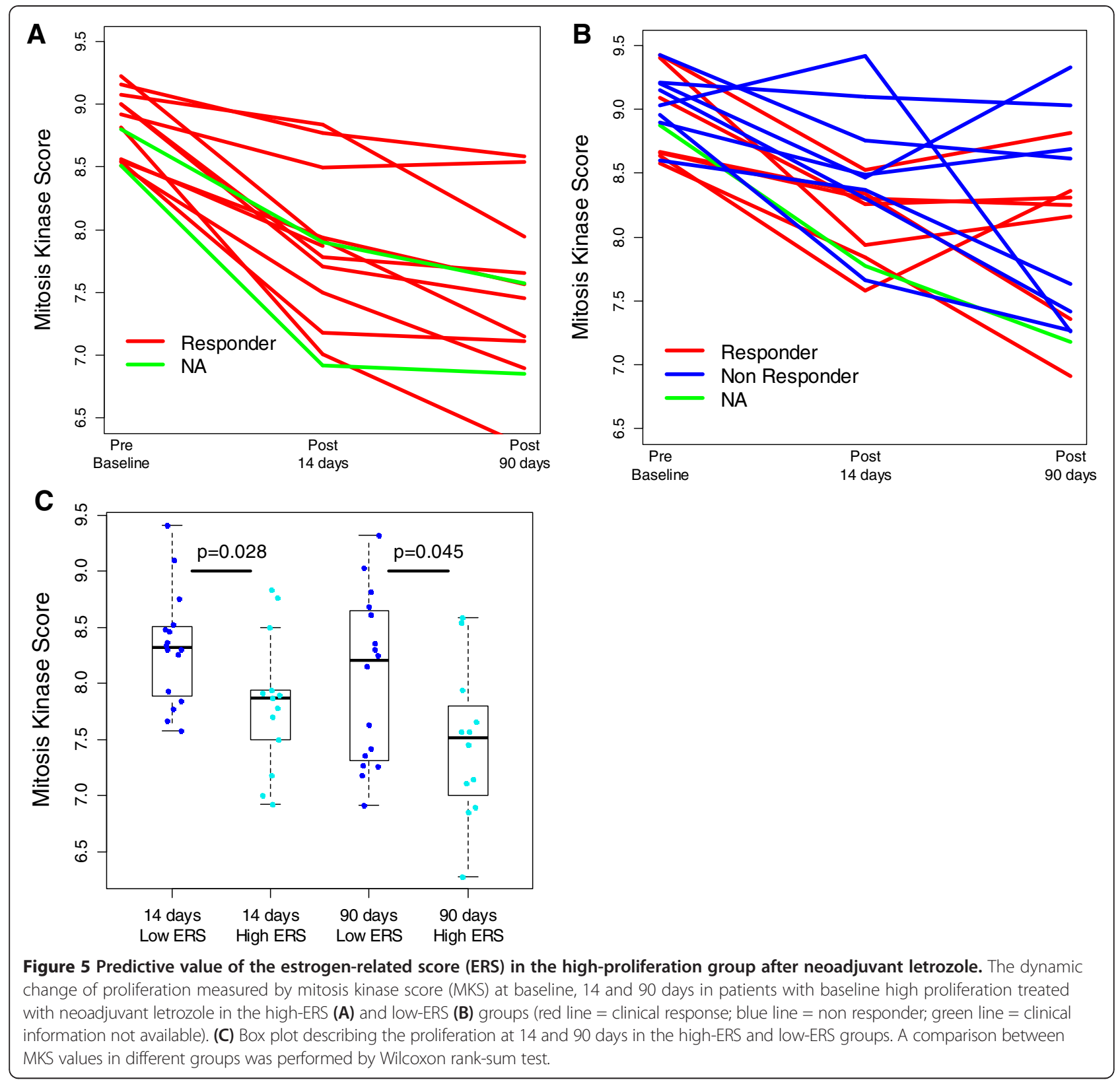

absolute increase for risk of late relapse after completion of 5 years of endocrine therapy, and therefore may be the best candidates for extended endocrine treatment. Among the low-proliferation cancers, the lowERS group had constantly higher risk of relapse over the 10-year period compared to low-proliferation, highERS cancers. Extended endocrine therapy in this group also deserves further study. The time-dependent interaction between proliferation and estrogen signaling in predicting recurrence may explain why biomarkers that do not take into account such information (PAM50, Oncotype DX) do not predict late recurrences well $[4,5]$.
The majority of the relapses within the first 2.5 years on tamoxifen occurred in the high-proliferation/low-ERS group. In a series of ER-positive patients treated with neoadjuvant letrozole, this group also had low clinical response rates and had minimal decrease in proliferation metrics [27]. These data suggest that the high-proliferation/ low-ERS group is enriched in tumors intrinsically resistant to both tamoxifen and letrozole and in part explain why the use of upfront aromatase inhibitors (AIs) was not superior to the sequence of tamoxifen followed by an aromatase inhibitor in unselected patients [28,29]. Clinical trials could be designed and investigate specific strategies to overcome 
intrinsic resistance in these molecular groups. Additionally, node-negative and node-positive tumors show a different pattern of relapse in this early period, indeed almost all the recurrences in the molecular groups different from the high-proliferation/low-ERS group occur in nodepositive cancers $(P=0.0008)$. The observation is consistent with findings in the BIG1-98 trial that showed a benefit from upfront letrozole compared to tamoxifen only in node-positive tumors during the short median follow up of 2.5 years [30].

Highly proliferative tumors relapsing after adjuvant tamoxifen had a progressively higher ERS score in late recurrences compared to early recurrences, but the same association was not observed in untreated tumors. One can speculate that early relapses are most common in tumors intrinsically resistant to endocrine treatment, while late recurrences occur also in tumors that could have relapsed earlier without treatment, but relapse was delayed due to adjuvant therapy. Our observation could also explain why in different reports the risk-reduction is modest around $20 \%$ for upfront AIs compared to tamoxifen [31], while it increases to $30 \%$ when tamoxifen is switched to an AI after 2 to 3 years [31], and the risk reduction is up to $50 \%$ when the AI is administered after 5 years of tamoxifen [1].

Our results are consistent with other reports and show that tumor size and nodal status remain independent prognostic factors. Clinical and molecular information, particularly nodal status should be used in combination for decision-making about extended endocrine treatments [32].

We acknowledge that the different characteristics of patients in the tamoxifen-treated and untreated cohorts call for caution in any comparison between the two groups. Also, our analysis is not based on data from randomized clinical trials but from prospectively assembled cohorts of cases for prognostic marker studies. The cohorts have been annotated and published in peer-reviewed journals [21], and the validity of clinical information has been demonstrated in several different studies $[6,8,33]$. The generalizability of our results was assessed in an independent cohort of tamoxifen-treated patients, and also supported by recently presented data by other groups [34,35].

\section{Conclusions}

Our findings suggest that patients with highly proliferative (high MKS or high GGI) and high-ER breast cancers (high expression of ER-related genes both adopted from Oncotype DX or from PAM50) have the highest absolute risk for late relapse tumors, despite the fact that their risk of recurrence is modest in the first 5 years on tamoxifen. These tumors could be the best candidates for extended endocrine therapy. Patients with low proliferation and lowER-related genes also remain at risk for late relapses, and benefit from extended endocrine treatment with aromatase inhibitors should be also assessed.
Early relapses (in the first 2.5 years) are highest in highly proliferative/low-ERS cancers, in particular in node-negative tumors, and this group also had minimal response to neoadjuvant letrozole. These findings suggest that this molecular group is enriched in tumors intrinsically resistant to endocrine therapy (both tamoxifen and letrozole) and in part can explain why upfront AIs were not superior to the sequence of tamoxifen followed by an $\mathrm{AI}$ in unselected patients.

Overall, the combined use of markers of proliferation and ER-related genes can inform the design of future adjuvant trials and assist in the selection of patients for extended endocrine treatment.

\section{Additional files}

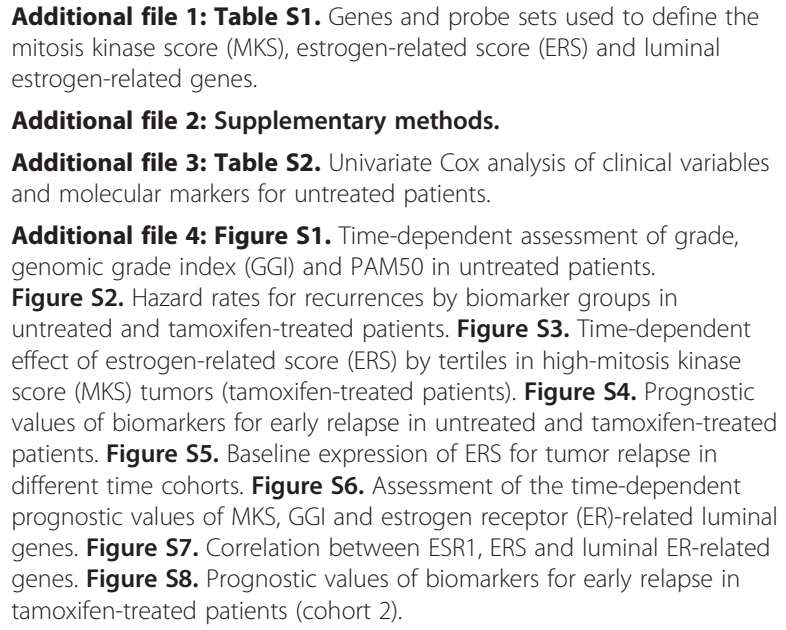

Additional file 1: Table S1. Genes and probe sets used to define the mitosis kinase score (MKS), estrogen-related score (ERS) and luminal estrogen-related genes.

Additional file 2: Supplementary methods.

Additional file 3: Table S2. Univariate Cox analysis of clinical variables and molecular markers for untreated patients.

Additional file 4: Figure S1. Time-dependent assessment of grade, genomic grade index (GGI) and PAM50 in untreated patients. Figure S2. Hazard rates for recurrences by biomarker groups in untreated and tamoxifen-treated patients. Figure S3. Time-dependent effect of estrogen-related score (ERS) by tertiles in high-mitosis kinase score (MKS) tumors (tamoxifen-treated patients). Figure S4. Prognostic values of biomarkers for early relapse in untreated and tamoxifen-treated patients. Figure S5. Baseline expression of ERS for tumor relapse in different time cohorts. Figure S6. Assessment of the time-dependent prognostic values of MKS, GGI and estrogen receptor (ER)-related luminal genes. Figure S7. Correlation between ESR1, ERS and luminal ER-related genes. Figure S8. Prognostic values of biomarkers for early relapse in tamoxifen-treated patients (cohort 2).

\section{Abbreviations}

Al: Aromatase inhibitors; DEFS: Distant event-free survival; ER: Estrogen receptor; ERS: Estrogen-related score; GGl: Genomic grade index; HER2: Human epidermal growth factor receptor 2; HR: Hazard ratio; MKS: Mitosis kinase score; T: Tumor.

\section{Competing interests}

W Fraser Symmans: Consultant or Advisory Role: Nuvera Biosciences (uncompensated); Stock Ownership: Nuvera Biosciences. C Sotiriou is named inventor on a patent application for the Gene expression Grade Index (GGI) used in this study. The other authors declare that they have no competing interests.

\section{Authors' contributions}

GB conceived and designed the study, performed the statistical analysis, contributed to the acquisition and collection of the gene expression data, data interpretation and writing the manuscript. LP and LG contributed to the study design, data analysis and interpretation and in writing the manuscript. TK contributed to the acquisition and collection of the gene expression data, statistical analysis, data interpretation and writing the manuscript. TI contributed to statistical analysis, data interpretation and writing the manuscript. YQ contributed to the statistical analysis and gene expression data normalization. AR, VM, MS, UH, SB, CS, BHK and WFS contributed to the acquisition and collection of the gene expression data, participated in data assembling and interpretation, and critically revised the manuscript. CMK, LS, AF, GDC and MZ participated in data assembling, analysis and interpretation and in writing the manuscript. All authors read and approved the final manuscript. 


\section{Acknowledgements}

Funding: the Fondazione Michelangelo for the advancement of the study and treatment of cancer grant to (GB), the Associazione Italiana per la Ricerca sul Cancro (AIRC) grant to (LG, IG 4915) and grant to (GB, MFAG 13428), the Breast Cancer Research Foundation (New York, NY) grant to (LP and WFS), the H.W.\&. Hector-Foundation (TK) and the Margarete Bonifer-Foundation (TK). The funders did not have any involvement in the design of the study, the collection, analysis and interpretation of the data, the writing of the article, or the decision to submit the article for publication.

\begin{abstract}
Author details
${ }^{1}$ San Raffaele - Scientific Institute, Milan, Italy. ${ }^{2}$ Yale Cancer Center, New Haven, CT, USA. ${ }^{3}$ J.W. Goethe University, Frankfurt, Germany. ${ }^{4}$ University Graduate School of Medicine and Dentistry, Okayama, Japan. ${ }^{5}$ University Medical Center Schleswig-Holstein, Campus Lübeck, Lübeck, Germany. ${ }^{6}$ Mater Misericordiae University Hospital, Dublin, Ireland. ${ }^{7}$ University Hospital Hamburg-Eppendorf, Hamburg, Germany. ${ }^{8}$ Gutenberg-University, Mainz, Germany. ${ }^{9}$ The University of Texas M. D. Anderson Cancer Center, Houston, TX, USA. ${ }^{10}$ Translational Research Unit and Istituto Toscano Tumori, Prato, Italy. ${ }^{11}$ Institut Jules Bordet, Univerité Libre de Bruxelies, Brussels, Belgium. ${ }^{12}$ Bioinformatics and Computational Genomics Laboratory, Institut de recherches cliniques de Montréal, Montreal, Canada.
\end{abstract}

Received: 19 April 2013 Accepted: 16 August 2013 Published: 23 September 2013

\section{References}

1. Jin H, Tu D, Zhao N, Shepherd LE, Goss PE: Longer-term outcomes of letrozole versus placebo after 5 years of tamoxifen in the NCIC CTG MA.17 trial: analyses adjusting for treatment crossover. J Clin Oncol 2012, 30:718-721.

2. Davies C, Pan H, Godwin J, Gray R, Arriagada R, Raina V, Abraham M, Alencar VHM, Badran A, Bonfill X, Bradbury J, Clarke M, Collins R, Davis SR, Delmestri A Forbes JF, Haddad P, Hou M-F, Inbar M, Khaled H, Kielanowska J, Kwan W-H, Mathew BS, Müller B, Nicolucci A, Peralta O, Pernas F, Petruzelka L, Pienkowski T, Rajan B, et al: Long-term effects of continuing adjuvant tamoxifen to 10 years versus stopping at 5 years after diagnosis of oestrogen receptorpositive breast cancer: ATLAS, a randomised trial. Lancet 2013, 381:805-816.

3. Amir E, Seruga B, Niraula S, Carlsson L, Ocana A: Toxicity of adjuvant endocrine therapy in postmenopausal breast cancer patients: a systematic review and meta-analysis. J Natl Cancer Inst 2011, 103:1299-1309.

4. Albain KS, Barlow WE, Shak S, Hortobagyi GN, Livingston RB, Yeh IT, Ravdin P, Bugarini R, Baehner FL, Davidson NE, Sledge GW, Winer EP, Hudis C, Ingle JN, Perez EA, Pritchard Kl, Shepherd L, Gralow JR, Yoshizawa C, Allred DC, Osborne $C K$, Hayes DF: Prognostic and predictive value of the 21 -gene recurrence score assay in postmenopausal women with node-positive, oestrogenreceptor-positive breast cancer on chemotherapy: a retrospective analysis of a randomised trial. Lancet Oncol 2010, 11:55-65.

5. Nielsen TO, Parker JS, Leung S, Voduc D, Ebbert M, Vickery T, Davies SR, Snider J, Stijleman IJ, Reed J, Cheang MC, Mardis ER, Perou CM, Bernard PS, Ellis MJ: A comparison of PAM50 intrinsic subtyping with immunohistochemistry and clinical prognostic factors in tamoxifen-treated estrogen receptor-positive breast cancer. Clin Cancer Res 2010, 16:5222-5232.

6. Loi S, Haibe-Kains B, Desmedt C, Lallemand F, Tutt AM, Gillet C, Ellis P, Harris A, Bergh J, Foekens JA, Klijn JG, Larsimont D, Buyse M, Bontempi G, Delorenzi M, Piccart MJ, Sotiriou C: Definition of clinically distinct molecular subtypes in estrogen receptor-positive breast carcinomas through genomic grade. J Clin Oncol 2007, 25:1239-1246.

7. Loi S, Haibe-Kains B, Desmedt C, Wirapati P, Lallemand F, Tutt AM, Gillet C, Ellis P, Ryder K, Reid JF, Daidone MG, Pierotti MA, Berns EM, Jansen MP, Foekens JA, Delorenzi M, Bontempi G, Piccart MJ, Sotiriou C: Predicting prognosis using molecular profiling in estrogen receptor-positive breast cancer treated with tamoxifen. BMC Genomics 2008, 9:239.

8. Symmans WF, Hatzis C, Sotiriou C, Andre F, Peintinger F, Regitnig P, Daxenbichler G, Desmedt C, Domont J, Marth C, Delaloge S, Bauernhofer T, Valero V, Booser DJ, Hortobagyi GN, Pusztai L: Genomic index of sensitivity to endocrine therapy for breast cancer. J Clin Oncol 2010, 28:4111-4119.

9. Zhang Y, Sieuwerts AM, McGreevy M, Casey G, Cufer T, Paradiso A, Harbeck N, Span PN, Hicks DG, Crowe J, Tubbs RR, Budd GT, Lyons J, Sweep FC, Schmitt M, Schittulli F, Golouh R, Talantov D, Wang Y, Foekens JA: The 76-gene signature defines high-risk patients that benefit from adjuvant tamoxifen therapy. Breast Cancer Res Treat 2009, 116:303-309.

10. Wang Y, Klijn JG, Zhang Y, Sieuwerts AM, Look MP, Yang F, Talantov D, Timmermans M, Meijer-van Gelder ME, Yu J, Jatkoe T, Berns EM, Atkins D, Foekens JA: Gene-expression profiles to predict distant metastasis of lymph-node-negative primary breast cancer. Lancet 2005, 365:671-679.

11. Desmedt C, Piette F, Loi S, Wang Y, Lallemand F, Haibe-Kains B, Viale G, Delorenzi M, Zhang Y, d'Assignies MS, Bergh J, Lidereau R, Ellis P, Harris AL, Klijn JG, Foekens JA, Cardoso F, Piccart MJ, Buyse M, Sotiriou C: Strong time dependence of the 76-gene prognostic signature for node-negative breast cancer patients in the TRANSBIG multicenter independent validation series. Clin Cancer Res 2007, 13:3207-3214.

12. Schmidt M, Bohm D, von Torne C, Steiner E, Puhl A, Pilch H, Lehr HA, Hengstler JG, Kolbl H, Gehrmann M: The humoral immune system has a key prognostic impact in node-negative breast cancer. Cancer Res 2008, 68:5405-5413

13. Minn AJ, Gupta GP, Padua D, Bos P, Nguyen DX, Nuyten D, Kreike B, Zhang $Y$, Wang $Y$, Ishwaran $H$, Foekens JA, van de Vijver M, Massague J: Lung metastasis genes couple breast tumor size and metastatic spread. Proc Natl Acad Sci USA 2007, 104:6740-6745.

14. Sotiriou C, Wirapati $P$, Loi S, Harris A, Fox S, Smeds J, Nordgren H, Farmer $P$, Praz V, Haibe-Kains B, Desmedt C, Larsimont D, Cardoso F, Peterse H, Nuyten D, Buyse M, Van de Vijver MJ, Bergh J, Piccart M, Delorenzi M: Gene expression profiling in breast cancer: understanding the molecular basis of histologic grade to improve prognosis. $J$ Nat/ Cancer Inst 2006, 98:262-272.

15. Filipits M, Rudas M, Jakesz R, Dubsky P, Fitzal F, Singer CF, Dietze O, Greil R, Jelen A, Sevelda P, Freibauer C, Muller V, Janicke F, Schmidt M, Kolbl H, Rody A, Kaufmann M, Schroth W, Brauch H, Schwab M, Fritz P, Weber KE, Feder IS, Hennig G, Kronenwett R, Gehrmann M, Gnant M: A new molecular predictor of distant recurrence in ER-positive, HER2-negative breast cancer adds independent information to conventional clinical risk factors. Clin Cancer Res 2011, 17:6012-6020.

16. Miller WR, Larionov A, Anderson TJ, Evans DB, Dixon JM: Sequential changes in gene expression profiles in breast cancers during treatment with the aromatase inhibitor, letrozole. Pharmacogenomics J 2012, 12:10-21.

17. Bianchini G, Iwamoto T, Qi Y, Coutant C, Shiang CY, Wang B, Santarpia L, Valero V, Hortobagyi GN, Symmans WF, Gianni L, Pusztai L: Prognostic and therapeutic implications of distinct kinase expression patterns in different subtypes of breast cancer. Cancer Res 2010, 70:8852-8862.

18. Paik S, Shak S, Tang G, Kim C, Baker J, Cronin M, Baehner FL, Walker MG, Watson D, Park T, Hiller W, Fisher ER, Wickerham DL, Bryant J, Wolmark N: A multigene assay to predict recurrence of tamoxifen-treated, nodenegative breast cancer. N Engl J Med 2004, 351:2817-2826.

19. Parker JS, Mullins M, Cheang MC, Leung S, Voduc D, Vickery T, Davies S, Fauron C, He X, Hu Z, Quackenbush JF, Stijleman IJ, Palazzo J, Marron JS, Nobel AB, Mardis E, Nielsen TO, Ellis MJ, Perou CM, Bernard PS: Supervised risk predictor of breast cancer based on intrinsic subtypes. J Clin Oncol 2009, 27:1160-1167.

20. van de Vijver MJ, He YD, van't Veer LJ, Dai H, Hart AA, Voskuil DW, Schreiber GJ, Peterse JL, Roberts C, Marton MJ, Parrish M, Atsma D, Witteveen A, Glas A, Delahaye L, van der Velde T, Bartelink H, Rodenhuis S, Rutgers ET, Friend $\mathrm{SH}$, Bernards R: A gene-expression signature as a predictor of survival in breast cancer. N Engl J Med 2002, 347:1999-2009.

21. Haibe-Kains B, Desmedt C, Loi S, Culhane AC, Bontempi G, Quackenbush J, Sotiriou C: A three-gene model to robustly identify breast cancer molecular subtypes. J Natl Cancer Inst 2012, 104:311-325.

22. Simon R, Lam A, Li MC, Ngan M, Menenzes S, Zhao Y: Analysis of gene expression data using BRB-ArrayTools. Cancer Inform 2007, 3:11-17.

23. Hess KR, Serachitopol DM, Brown BW: Hazard function estimators: a simulation study. Stat Med 1999, 18:3075-3088.

24. Jatoi I, Anderson WF, Jeong JH, Redmond CK: Breast cancer adjuvant therapy: time to consider its time-dependent effects. J Clin Oncol 2011, 29:2301-2304.

25. Bellera C, MacGrogan G, Debled M, de Lara C, Brouste V, Mathoulin-Pelissier S: Variables with time-varying effects and the Cox model: Some statistical concepts illustrated with a prognostic factor study in breast cancer. BMC Med Res Methodol 2010, 10:20.

26. Kim C, Tang G, Pogue-Geile KL, Costantino JP, Baehner FL, Baker J, Cronin MT, Watson D, Shak S, Bohn OL, Fumagalli D, Taniyama Y, Lee A, Reilly ML, Vogel VG, McCaskill-Stevens W, Ford LG, Geyer CE Jr, Wickerham DL, 
Wolmark N, Paik S: Estrogen receptor (ESR1) mRNA expression and benefit from tamoxifen in the treatment and prevention of estrogen receptor-positive breast cancer. J Clin Oncol 2011, 29:4160-4167.

27. Ellis MJ, Tao Y, Luo J, A'Hern R, Evans DB, Bhatnagar AS, Chaudri Ross HA, von Kameke A, Miller WR, Smith I, Eiermann W, Dowsett M: Outcome prediction for estrogen receptor-positive breast cancer based on postneoadjuvant endocrine therapy tumor characteristics. J Natl Cancer Inst 2008, 100:1380-1388

28. van de Velde CJ, Rea D, Seynaeve C, Putter H, Hasenburg A, Vannetzel JM, Paridaens R, Markopoulos C, Hozumi Y, Hille ET, Kieback DG, Asmar L, Smeets J, Nortier JW, Hadji P, Bartlett JM, Jones SE: Adjuvant tamoxifen and exemestane in early breast cancer (TEAM): a randomised phase 3 trial. Lancet 2011, 377:321-331.

29. Regan MM, Neven P, Giobbie-Hurder A, Goldhirsch A, Ejlertsen B, Mauriac L, Forbes JF, Smith I, Lang I, Wardley A, Rabaglio M, Price KN, Gelber RD, Coates AS, Thurlimann B: Assessment of letrozole and tamoxifen alone and in sequence for postmenopausal women with steroid hormone receptor-positive breast cancer: the BIG 1-98 randomised clinical trial at 8.1 years median follow-up. Lancet Oncol 2011, 12:1101-1108.

30. Thurlimann B, Keshaviah A, Coates AS, Mouridsen H, Mauriac L, Forbes JF, Paridaens R, Castiglione-Gertsch M, Gelber RD, Rabaglio M, Smith I, Wardley A, Price KN, Goldhirsch A: A comparison of letrozole and tamoxifen in postmenopausal women with early breast cancer. N Engl J Med 2005, 353:2747-2757.

31. Dowsett M, Cuzick J, Ingle J, Coates A, Forbes J, Bliss J, Buyse M, Baum M, Buzdar A, Colleoni M, Coombes C, Snowdon C, Gnant M, Jakesz R, Kaufmann M, Boccardo F, Godwin J, Davies C, Peto R: Meta-analysis of breast cancer outcomes in adjuvant trials of aromatase inhibitors versus tamoxifen. J Clin Oncol 2010, 28:509-518.

32. Tang G, Cuzick J, Costantino JP, Dowsett M, Forbes JF, Crager M, Mamounas EP, Shak S, Wolmark N: Risk of recurrence and chemotherapy benefit for patients with node-negative, estrogen receptor-positive breast cancer: recurrence score alone and integrated with pathologic and clinical factors. J Clin Oncol 2011, 29:4365-4372.

33. Bianchini G, Qi Y, Alvarez RH, Iwamoto T, Coutant C, Ibrahim NK, Valero V Cristofanilli M, Green MC, Radvanyi L, Hatzis C, Hortobagyi GN, Andre F, Giann L, Symmans WF, Pusztai L: Molecular anatomy of breast cancer stroma and its prognostic value in estrogen receptor-positive and -negative cancers. J Clin Oncol 2010, 28:4316-4323.

34. Sgroi D, Sestak I, Cuzick J, Zhang Y, Schnabel C, Erlander M, Goss P, Dowsett M: Comparative performance of breast cancer index (bci) vs. oncotype $\mathrm{dx}$ and ihc4 in the prediction of late recurrence in hormonal receptor-positive lymph node-negative breast cancer patients: a TransATAC study. Cancer Res 2012, 72:S1-9.

35. Dubsky P, Brase JC, Fisch K, Jakesz R, Singer CF, Greil R, Dietze O, Weber KE, Petry C, Kronenwett R, Rudas M, Knauer M, Gnant M: The EndoPredict score identifies late distant metastases in ER+/HER2- breast cancer patients. Cancer Res 2012, 72:S4-3.

doi:10.1186/bcr3481

Cite this article as: Bianchini et al:: Proliferation and estrogen signaling can distinguish patients at risk for early versus late relapse among estrogen receptor positive breast cancers. Breast Cancer Research 2013 15:R86.

\section{Submit your next manuscript to BioMed Central and take full advantage of:}

- Convenient online submission

- Thorough peer review

- No space constraints or color figure charges

- Immediate publication on acceptance

- Inclusion in PubMed, CAS, Scopus and Google Scholar

- Research which is freely available for redistribution 